\title{
TEACHING AND ASSESSING MIND MAPS
}

Jennifer Wright

Cape Peninsula University of Technology

The purpose of literacy interventions in higher education is to develop students' competencies so they could cope with the literacy demands of their academic studies. One such competency is mind mapping. The literature provides strong arguments that mind mapping provides students with valuable organisational and heuristic tools and offers guidelines on how to draw mind maps. The issue of assessing mind maps is, however, generally absent.

This paper explores the characteristics of effective mind maps, their benefits and importance at all levels of education, as well as the issue of whether or not they should be assessed. It seems that too little attention has been paid to the value of mind mapping in higher education; and that the assessment of mind maps requires further debate by those with an interest in creative teaching at tertiary level.

\section{BACKGROUND AND RATIONALE}

At the former Peninsula Technikon (now the Bellville campus of the Cape Peninsula University of Technology), many entry-level students are under prepared for higher education and so find it difficult to meet their lecturers' academic expectations. The academic difficulties of these students may be compounded by the fact that the medium of instruction is English while most of them are first language Xhosa or Afrikaans speakers.

Over the years, lecturers of Communication (typically an entry-level subject) have embarked upon various initiatives to address students' learning challenges. I was one of six lecturers who piloted a generic academic literacy programme called LEAP (Learning in English for Academic Purposes) with first year student teachers in the mid-1990s. One of the competencies we taught was mind mapping, a technique for summarising and organising information.

Mind mapping has been part of my first year Communication curriculum ever since. It offers students a creative and flexible method of note taking (by contrast with traditional linear notes); and provides students with a tool for organising information for their assignments.

I usually begin a mind mapping session by explaining the rationale for mind mapping. I discuss right brain function (creative, generative but disorganised) and left brain function (linear, organised), plus how these functions relate to brainstorming and mind mapping - in line with Novak's (2004) claim that one cannot merely teach students to produce such maps because they need to understand the way the brain organises information. With the students' input, I then model the technique of brainstorming, using whatever subject matter is topical. 
Using colour or shape, we identify categories of information. These categories become the key branches of a mind map. Linking lines are used to indicate levels and relationships among details. The categories thus serve much the same function as sub-headings in an essay. The advantage for the students is that they actively participate in the process of brainstorming a subject, identifying key ideas, drawing a mind map, and viewing the finished item to guide them in subsequently devising their own (see a typical example, Appendix A).

I generally set a homework task next so students can practise what they have learned. In the past two years, for example, students have planned an interview to gather information for a biography, using brainstorming and a mind map. Students plan an interview by brainstorming the required categories of information for a biography. During the interview itself, students fill in details in a mind map skeleton. The mind map is then used as a plan for writing the biography. Subsequently, students submit their biographies with the mind maps attached so that the relationship between the mind maps and biographies may be discerned.

My concern has been that the students' mind maps tend to lack depth (in terms of levels of information); there are illogical links and unclear relationships among details; there is often duplication or overlap of categories (the names of categories differ but they should be included one category, such as 'education' and 'schooling'); and there is often no clear visual separation of details in two adjoining categories, making it difficult to establish where a point belongs. Some mind maps comprise four or five subheadings, each with a linear list below in fact many of the mind maps do not look at all like the mind map I have modelled for them at all.

In lectures, I discuss students' mind maps and advised them on how to improve their mind maps: they should use key words only (many had been rather wordy); have a visual hierarchy of information (somewhat like a main heading looking different to a subheading); keep details within categories of information visually distinct; and clearly link the details.

In a test one semester, I asked students to take notes from a written text and represent the notes in mind map format. Students had been informed ahead of the time that they would be asked to draw a mind map to summarise information as part of the test.

The responses of the students to the task raised the issue of assessing mind maps. I decided that content would carry $80 \%$ of the mark; visual representation of the information carried $20 \%$, with a mark of $5 \%$ for each of these four criteria:

- Key ideas evident

- Hierarchy shown

- Groupings distinct

- Links clear

Although students fared quite well in identifying the salient points of the content, their visual representation was often very confusing. While the test question did not explicitly mention the four sub-criteria, we had discussed the qualities of an effective mind map during class.

In discussion with the class after the test, some students stated that they would have preferred it if I had not assessed the visual clarity of their mind maps. Having modelled the technique for them, having given them an opportunity to practise the technique, and then discussed it with them in class, I did not agree, at the time. However, I wondered why their mind maps 
were so different from the one I had modelled. Subsequently, I concluded that I had perhaps not given the students enough practice in implementing the four criteria. I also concluded, from the characteristics of some of their mind maps, that at least some of the students had previously been taught mind mapping in a very different way to the way I had taught it and that these earlier learnings had persisted. I also eventually realised that, as they were first year students, they might have drawn better mind maps if I had set out the four sub-criteria of visual representation. In addition, brief conversations with colleagues on the issue of assessing mind maps revealed that while they supported mind mapping a technique, they felt that assessment would always be problematic.

Following this experience, I decided to conduct a small research project on mind maps. My intention was to examine the literature on the subject of mind maps, and, from there, answer these questions: 1. How can I improve the way in which I teach students to use mind maps to support their studies? 2. Are mind maps assessable? (and, if so, what criteria should be used to assess them?) and 3. Should mind maps be assessed?

In this article, I will review the research project that I undertook to explore these questions and the findings and conclusions that emerged. I will begin by reviewing literature on mind mapping: its history, benefits, techniques and the issue of assessment.

\section{LITERATURE REVIEW}

Tony Buzan, a British brain researcher, who invented the method in the 1970s, coined the term 'mind mapping' (Lumsdaine \& Lumsdaine, 1995:55). 'Mind mapping' is sometimes given other names, including 'webbing' and 'concept mapping' (Shih, 1992; Novak \& Gowin, 1984). Steyn and Boer (1998) point out, however, that 'concept maps' tend to be strongly linear whereas the Buzan structure, the 'mind map', is more appropriate for fostering 'whole brain learning'. Irrespective, a mind map, mind web or a concept map represents a technique of representing information in a concise visual format: Bhattacharya (2000:1) describes it as a 'visual organising technique'.

Mind maps are purported to offer many educational advantages, such as these:

Buzan (1995:9) explains that mind maps can be used 'for recording, organising, remembering, creative thinking and problem-solving'. Mind mapping was originally called 'pattern noting' as it was initially developed as a note-taking technique that shows the patterns and relationship among facts or ideas. This feature of representing relationships is most valuable and is not as easily found in linear notes.

Chaffe (1994:438) emphasises the value of mind maps for writing: associations are indicated in mind maps; through these associations, mind maps provide organisational structure. The structure forces one to grapple with and depict relationships. It also allows for later revision of the original structure to include new information.

Buzan (1995:85) claims that drawing mind maps saves time as key words are used. Vygotsky's (1987) work would support the value of using key words only, but for a reason other than times-saving: according to him, the L2 (second language) learner's cognitive load is lowered when key words, instead of full sentences, are used because the learner can 
concentrate on core concepts as s/he is not distracted by the demands of producing a full, coherent sentence.

Buzan (1993:225-228) also notes other advantages of mind maps:

1. They are ideal where understanding, not writing, is the issue (understanding should presumably precede writing);

2. They encourage deep versus surface learning (they depict levels of relationship);

3. They show where there are incorrect associations among ideas.

Rogoff \& Lave (1984:247) note the relationship between mind mapping and memory: 'A map is a kind of metaphor'. As words and images are linked in visual representation, this aids memory. The latter function would fit in with Ausubel's (1968) meaningful learning theory, namely that we learn the new by relating it to the existing cognitive construction, with possible shifts in the latter occurring to accommodate the new information.

Vygotsky's (1987) Zone of Proximal Development theory (ZPD) reminds us that the process of learning new information does not occur in a vacuum: moving from a particular level of development (in Piaget's terms) towards a particular performance level requires collaboration with more advanced others, such as teachers, mentors or peers. Angelil-Carter (1994) considers that mind maps can reveal a student's prior knowledge before it is extended; and she (1994) suggests that educators use mind maps to drive the ZPD through the insights they provide. The mind map is thus like a snapshot of a thinking process captured at a particular moment in time. It allows not just the learner, but the teacher too, to step away and observe the thinking process, the overall groupings of concepts and the links among these groups. In addition, levels of detail and relationships within each group are evident.

Other stated benefits are that mind mapping supports both inductive and deductive thinking (Clarke, 1991); it improves textual comprehension (Walker \& Mitchell, 1994:26-28); it is a study tool that can be used to help under prepared students in Mathematics and Science (Steyn \& Boer, 1998:1-10); it promotes creative thinking (Petrini, 1994:15 and Anderson, 1993:4146); and is a critical tool for improving writing (Zipprich, 1997:391-395).

Most authors pay attention to the importance of the structure of mind maps. For example, Buzan (1995:95) describes a definite process that should be followed in designing the mind map: once one has brainstormed, one can search for connections among concepts; then a form of hierarchy becomes evident. Buzan (1995:93) emphasises that a mind map should have a definite structure: a central idea, with the relative importance of each other idea clearly shown. The more important ideas are nearer the centre and those of lesser importance are nearer the edges. The relationship among ideas is depicted by what Buzan (1993:80) describes as a hierarchy among these ideas: 'second, third and fourth branch levels'. Links between concepts are also immediately recognisable 'because of their proximity and connection'.

Chaffee (1994:275) confirms the importance of a definite structure, stating: 'Your ideas should be written on lines that are connected to other lines, in order to express clearly the relationship between the various ideas'. The visual aspect of clear relationships is also stressed by Buzan (1993:91), who prescribes for effective mind mapping 'the laws of layout'.

Assessment is scarcely discussed in the literature. Yet some believe mind maps can and even should be assessed: to quote Buzan (1993), 'If the purpose of an examination is to test students' knowledge and understanding rather than their writing ability, the Mind map is the 
ideal solution'. Novak (2004) also discusses the issue of assessing of cognitive mapping and endorses the practice by saying:

When concept maps are used in instruction, they can also be used for evaluation. There is nothing written in stone that says multiple choice tests must be used from grade school through university, and perhaps in time even national achievement exams will utilize concept mapping as a powerful evaluation tool. This is a chicken-and-egg problem because concept maps cannot be required on national achievement tests, if most students have not been given opportunities to learn to use this knowledge representation tool. On the other hand, if state, regional, and national exams would begin to include concept maps as a segment of the exam, there would be a great incentive for teachers to teach students how to use this tool. Hopefully, by the year 2061, this will come to pass.

Steyn and Boer (1998) used mind map assessment during a research project aimed at improving under prepared students' mathematics and science results. Their research of the literature had led them to understand that mind maps would assist their students to overcome surface approaches so often associated with rote learning. Interestingly, their study does not question whether assessment is possible or advisable: they simply taught students the techniques advocated by Buzan \& Buzan (1997), told them to apply the three A's suggested by the authors (Accept the technique as an effective study tool; Apply it to relevant subject content; and Adapt the structure only once you are more skilled and confident in using it), gave them a task in which they were requested to apply the Buzan format strictly, and assessed their mind maps. They were pleased with the results.

In the following section, I will describe the research that I conducted to explore students' views on what constitutes an effective mind map, as well as their views on mind map assessment.

\section{METHODOLOGY}

\section{Planning}

A Radiography colleague and I decided to explore issues around mind maps during a shared lecture. We chose a first year group of Radiography students that I had not previously taught. The research site was the Radiography Department of the former Peninsula Technikon, situated at Groote Schuur Hospital.

The class comprised twenty-five first years students from a variety of cultural and language backgrounds; there was almost an equal number of males and females. Only two students used English as their home language.

During our joint lecture, my task, broadly, would be to engage students in an exploration of various aspects of mind mapping; my colleague would teach students the functions of the kidney and, wherever possible, make language aspects and meaning clear to the group. There would be a task for homework incorporating both mind mapping and essay writing (on the subject of kidney function). 
The lecture was to be video-recorded and a transcript made of relevant sections (i.e. regarding mind maps and their assessment). After the lecture, students would respond to a reflection sheet (see Appendix B) as well as a questionnaire (see Appendix C).

On submission of their mind maps and essays, the Radiography lecturer and I would examine these for the following purposes: I would ascertain how they had drawn their mind maps and note to what extent they had incorporated the aspects that they had identified as characteristics of an effective mind map; the Radiography lecturer intended to note the relationship between the mind maps and the essays that the students wrote.

\section{OBSERVATIONS AND DISCUSSION}

\section{The lecture}

At the beginning of the lecture, we gave the students a broad lecture and task overview.

I then displayed three different mind maps on the pin board and asked students to examine these closely. Students were asked to select the most effective one of the three mind maps. Only one of these incorporated the features that, according to the literature, constitute a 'good' mind map. I based the other two on typical student mind maps that I had seen over time (see Appendix D).

The students all chose the mind map that, in my view, was the clearest and easiest to follow. They then had to identify the criteria on which they had based their selection. I told them that we would use the criteria that they had chosen to assess the mind maps that they were going to do later.

Lively discussion followed. Students eventually generated a lengthy list of criteria, from which they settled on two broad categories: Content and Presentation (the same two categories that I had used in assessing the students' mind maps in the test mentioned earlier).

Well into our allotted discussion time, when consensus on these two categories had been reached, a student raised the issue of 'individual perception'. Here is a transcript of the pertinent part of the dialogue:

Lecturer: All right. Is there another category that we perhaps...that you feel was there that we haven't touched on here? We've got Content as one criterion that would be used in the assessment of a mind map, we've got Presentation.

Student: Maybe it's as you perceive it and as your brain perceives it...your own manner of saying it.

Lecturer: Individual perception? This you say is another category? Do you all agree with that? So, if someone is assessing your mind map, they've also got to take into account that it's your own way of seeing it?

Students: Ja (chorus) 
Student: The thing about a mind map is that it must make it clear for you, cos what you sketch or write may not be clear for anyone else so they can come and see that it's absolutely, like, deurmekaar, but as long as I can understand what's going on, and I can follow where I'm going, that's why I think that's actually a very important category.

Since Individual Perception was the third assessment criterion, students were then asked to assign weights to each category to ensure fair weighting when we assessed their mind maps.

After some time, the new category of Individual Perception, from being non-existent initially, was allocated $60 \%$ of the weight, with only $20 \%$ for each of the other two categories (Content and Presentation). In effect, this new criterion and its weight meant that each student would be the only one qualified to assess his or her own mind map. A lecturer could assess the content and presentation, but each would count only $10 \%$.

Time constraints prevented further discussion. My colleague revised the functions of the kidney, while students took mind map notes. Before the lecture, she provided the students with an outline of the lecture, to assist them in structuring their mind maps. Students were also reminded that mind maps would be submitted and assessed along with their essays.

Following the lecture, students were asked to reflect on the lecture and respond to questionnaires.

\section{Questionnaires and reflections}

Written reflections on the joint lecture (Appendix B) and responses to the questionnaire (Appendix C) were examined. The most illuminating points were these:

- $89 \%$ of students had previously experienced mind mapping, but only two had learned any special technique or format like the one that I had shown them; and

- $\quad 89 \%$ said that mind maps should not be used for assessment.

The first of these points indicates that the students might have come to the lecture with preconceptions of mind mapping.

Reasons for the second opinion were in line with these written reflections:

- You write whatever you think and it is convenient for you.

- Everybody is not comfortable with mind mapping.

- Mind maps are not notes, it's your understanding in your own way that you can relate to.

- Everyone's technique is different; there would be no correct way of assessing it.

- A mind map is your own personal way of understanding and remembering. What you write down and understand, someone else may not.

- My mind map is personal, not clear to all.

Students clearly felt strongly about this point. 


\section{The mind maps}

Our subsequent examination of students' mind maps revealed that not one clearly resembled the mind map that the class members themselves had earlier identified as the most effective. Most mind maps were what Buzan (1995:112) refers to as 'Mind maps that aren't really Mind maps' but 'clustering' or 'spider' diagrams. In other words, the students' 'mind maps' tended to be linear lists of notes arranged at the ends of 4 or 5 legs, as this diagram shows:

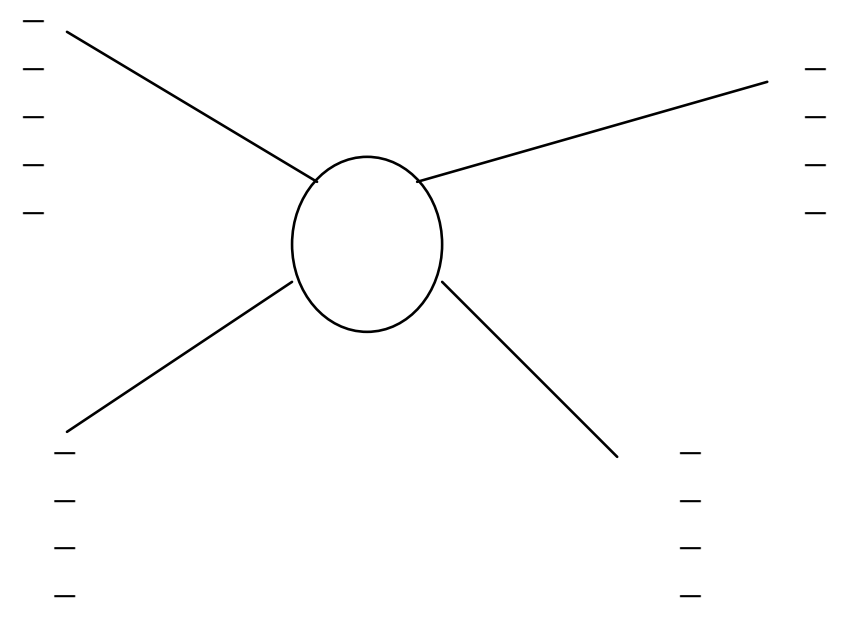

Angelil-Carter (1994:129) notes that spider maps are suited to initial planning and are typically used by students who have had minimal prior use of mind maps. She also notes that concept maps are more appropriate for representing deeper understandings and analysis of, for example, texts. Thus, while spider maps are not without their uses, as they do involve initial planning and categorisation, they do not indicate relationships among the listed items below each subheading.

Novak (2004:7) discusses the issue of depicted relationships in mind maps:

It is important to help students recognize that all concepts are in some way related to one another ... Students often comment that it is hard to add linking words onto their concept map. This is because they only poorly understand the relationship between the concepts and it is the linking words that specify this relationship.

This explains why lists typically used in spider webs lack complexity, with only key categories identified.

Angelil-Carter (1994) also questioned why some students adopted and used the technique effectively, while others struggled and used it in a fairly linear way. She (1994:139) considers several possibilities:

(a) Students have difficulty transferring the notion of categories and sub-categories from the traditional linear format, such as is used in textbooks, to the mind maps where the categories are usually organised in a non-linear way. I believe that a way to address this is, when teaching mind mapping, one should discuss and compare the function, similarities and differences between headings, subheadings 
and minor subheadings in textbooks and the levels of mind maps. (Students generally encounter different levels of subheadings in textbooks.)

(b) Students have difficulty 'unlearning' earlier (usually linear) systems of notetaking. I believe that this is certainly possible. From the comment made by one of the students (see comments under Questionnaires and reflections in previous section), some students are 'not comfortable' with the technique. This is unsurprising when one is using any new technology. Only with practice does any new technique become 'comfortable' for the user. Students therefore need much practice, exposure to more examples and discussion before they can be expected to improve their mind map technique and stop automatically wanting to use the familiar linear notes.

(c) There may be a lack of confidence about summarising in the medium of another language (in which the student may have limited linguistic control) when using a new technique. This would certainly be an inhibiting factor, depending on the student's level of proficiency. With two exceptions, all the Radiography students spoke or used English as another (second or third) language. Perhaps a few practice drafts of mind mapping the same information, with lecturer responses to at least one draft, would help students to improve.

From the experience of the lecture and the findings from the questionnaire and students' reflections, the question arises: should mind maps have any particular structure and (therefore) appearance if they are for the sole use of the individual and are to accommodate the unique/individual perceptions of the individual? If the first year Radiography students are the best judges of this matter, then the answer is 'no'. While this view is certainly understandable, the literature persuades me that teaching students more effective mind mapping techniques will benefit them. More recently, I have taught mind mapping techniques and layout more prescriptively to a new student group, taking into account what I had learned about making criteria (repeatedly) explicit, and allowing for more practice. I explain the value of being able to construct well-organised mind maps, and ask students to try the new technique with an open mind. Students have taken mind map notes from a video or a lecture, then revised them before submitting them for comment. The mind maps that these students produce are generally clearer than those discussed previously; there are also improvements in the use of key words, links and hierarchy. This seems to indicate that what Buzan (1993:88) asserts is so: mind mapping is a learned skill. However, like all skills, it needs practice to achieve maximum usefulness.

I have chosen not to assess mind maps formally again, although I may review my decision after further research and discussion. My assessment practice is informed by the belief that assessment practices have the potential to change student learning because they tell students what is valued. I continue to allocate informal marks (i.e. not credit-bearing) for various aspects of mind maps (for example, I may allocate 6/10 for visual clarity; 8/10 for content; $6 / 10$ for using key words only; and 7/10 for relationship links). These marks offer students a convenient interpretation of their technique so that they can continue to improve.

\section{CONCLUSION}

In answer to my research questions, I believe that, through my research, I have learned how to improve the way in which I teach mind mapping. I have gained insight through my mistakes and now appreciate the need to be sensitive to the fears of entry-level students who may have 
limited experience of the technique, and who do not particularly want to change from the security of tried and tested linear methods. I have learned that students need exposure to, and discussion of, multiple examples of mind maps. They must have time to practise the technique so that they may make mind mapping their own, developing an appreciation of the possibilities that mind maps offer them. If practice is the key to students improving their mind mapping techniques and gaining all the assumed benefits, then all lecturers should teach mind mapping. At present it seems that too few lecturers in our institution know about mind mapping therefore they neither teach the technique to their students nor encourage students to use mind maps to engage with core concepts in their subjects. Perhaps because mind maps can look decorative, even 'pretty', they are erroneously viewed as 'fun', not to be taken too seriously.

Whether or not mind maps should be assessed depends on how well students have been taught to use them. As mentioned, the amount of exposure that they have had to mind maps, the amount of practice that they have had, and the amount of guidance that they have received in response to their initial efforts are significant factors. Perhaps it would be beneficial if students learned to assess their own mind maps, with 'personal usefulness' as a major criterion instead of 'personal interpretation'. This might encourage students to consider their mind maps more objectively.

In conclusion, the technique of mind mapping needs to be taught thoroughly, explicitly, unhurriedly and over an extended period of time. Once taught, the investment of time and effort will pay dividends. If lecturers of all subjects learn to use the technique themselves and teach it to their students, it could be a dynamic means by which students learn to uncover for themselves areas of conceptual confusion or deepen their understanding of complexities in their discipline, harnessing their creative and linear abilities to do so.

\section{REFERENCES}

ANDERSON, JV. 1993. Mind mapping: a tool for creative thinking. Business Horizons, 36 (1):41-46.

ANGELIL-CARTER, S. 1994. Cognitive mapping within the writing process. In AngelilCarter, S., D. Bond, M. Paxton \& L. Thesen (Eds) Language in academic development. Cape Town: University of Cape Town. 125-149.

AUSUBEL, DP. 1986. Educational Psychology: A Cognitive View. New York: Holt, Rinehart and Winston, Inc.

BHATTACHARYA, M. 2000. Cognitive maps as a tool for discussion in a computersupported collaborative learning environment. (Web document). http://www.sccs.chukyo-u.ac.jp/ICCS/olp/o4-12/04-12.htm. Accessed 16 September 2005.

BUZAN, T. 1993. The mind map book. London: BBC Books.

BUZAN, T. 1995. Use your head. London: BBC Books.

CHAFFEE, J. 1994. Thinking critically. Boston: Houghton Mifflin. 
CLARKE, JH. 1991. Using visual organisers to focus on thinking. Journal of Reading, 34 (7): 526-534.

LUMSDAINE, E \& M LUNSDAINE. 1995. Creative problem-solving. London: McGrawHill.

NOVAK, JD. 2004. The Theory Underlying Concept Maps and How to Construct Them. (Web document.) Available: http://cmap.coginst.uwf.edu/info/printer.html. 31 October.

NOVAK, JD \& DB GOWIN. 1984. Learning how to learn. Cambridge: Cambridge University Press.

PETRINI, CM. 1994. Creating creativity. Training \& Development, 48(11): 11-15.

ROGOFF, B \& J LAVE (EDS) 1984. Everyday cognition. London: Harvard University Press.

SHIH, M. 1992. Beyond comprehension exercises in the ESL Academic Reading Class. In TESOL Quarterly, 26(2) :289-318.

STEYN, T \& AL BOER. 1998. Mind mapping as a study tool for underprepared students in mathematics and science. Journal of Ethnology, 21(3): 125-131.

VYGOTSKY, LS. 1987. Thinking and speech. In Rieber, RW \& AS Carton (eds), The collected works of LS Vygotsky, Vol. 1: Problems of General Psychology. New York: Plenum Press.

WALKER, G \& PD MITCHELL. 1994. Using cognitive mapping to improve comprehension of text. In Hoey, R (Ed.) Aspects of educational and training technology XXVII: Designing for Learning, Ch. 5. London: Kogan Page.

ZDANEK, M. 1985. The Right-Brain experience: an intimate programme to free the powers of your imagination. London: Corgi Books.

ZIPPRICH, M. 1997. Web-making: an easy but critical first step to better writing. Reading \& Writing Quarterly, 13(4): 391-395.

\section{Biographic Note}

Jennifer Wright is a Language Coordinator/Lecturer at the Faculty of Science, Cape Peninsula University of Technology (Bellville campus). Her research focuses on issues in the sociology of education such as language and literacy in the context of teaching and learning in higher education in South Africa and content and language integration. She has also written several content and language integrated books/workbooks. Contact details: wrightj@ cput.ac.za/+27 219596432 (O). 


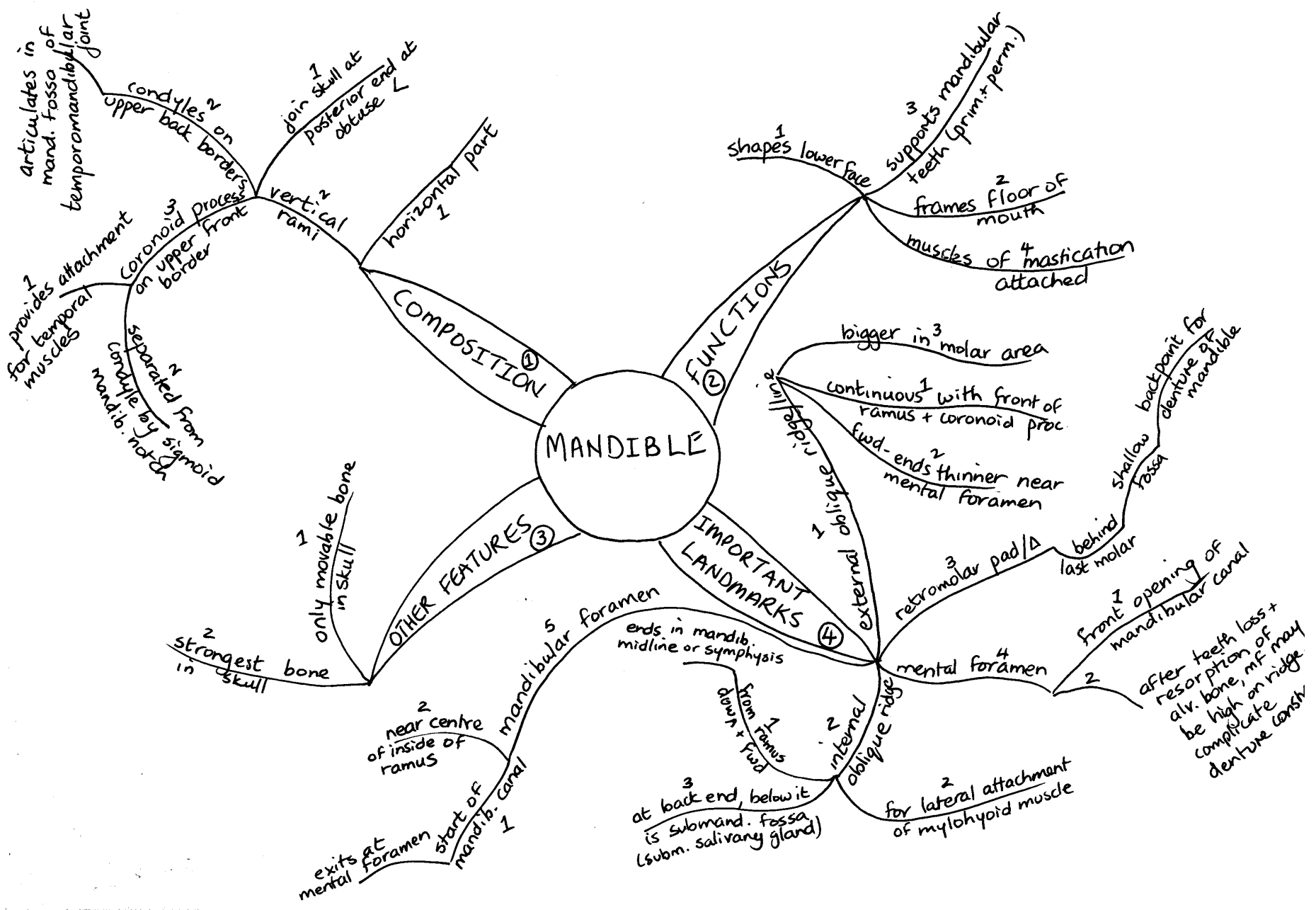


APPENDIX B: REFLECTIONS ON JOINT LECTURE: RADIOGRAPHY AND COMMUNICATION SKILLS

In the space provided below each of the following questions, please respond to these questions in as much detail as you can. If you do not have enough space, please write on the back of this sheet.

Thank you for your participation and help!

1. What did you like/learn from/find useful during this lecture? Please give reasons for your responses.

2. What did you NOT like/learn from/find useful during this lecture? Please explain.

3. Do you have any suggestions for improvements?

4. Any other comments? 
APPENDIX C: QUESTIONNAIRE FOR RADIOGRAPHY I STUDENTS

PLEASE HELP ME WITH MY RESEARCH BY RESPONDING TO THE FOLLOWING QUESTIONS.

SURNAME: FIRST NAME/S

Please circle the response that is true for you, or respond to the question in the space provided.

1. Did you learn the technique of mind mapping when you were in high school? YES NO

2. If your answer in (1.) was NO, where did you learn it (if before our joint lecture?)

3. Were you taught a very specific technique of mind mapping? YES NO

4. If your answer in (3.) was YES, please illustrate briefly on the back of this page (i.e. do a small mind map about your areas of study this year)

5. Do you think you may use the technique of mind mapping in lectures in future? YES NO

6. Give a reason for your answer in (5.)

7. Do you think mind maps should be used for assessment purposes? YES NO

8. Please give a reason for your response to question 7 .

Thank you very much for taking the time to respond to these questions.

Language and Communication skills lecturer 
$J$ Wright

APPENDIX D: EXAMPLES OF STUDENT MIND MAPS

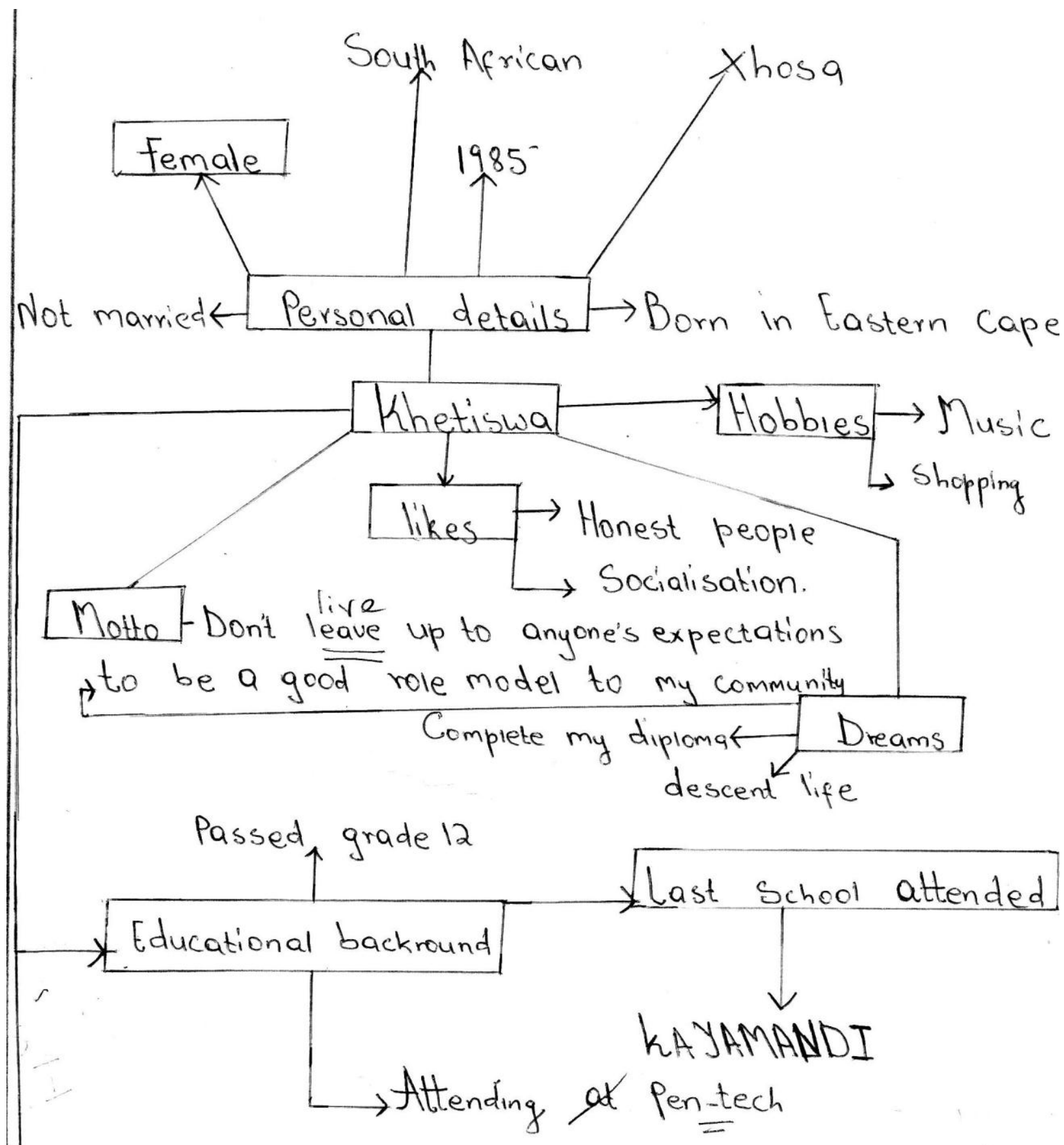

role model

Honourable Dr Nelson Rolihiahla Mandela

Per Linguam 2006 22(1):23-38

37

http://dx.doi.org/10.5785/22-1-59 


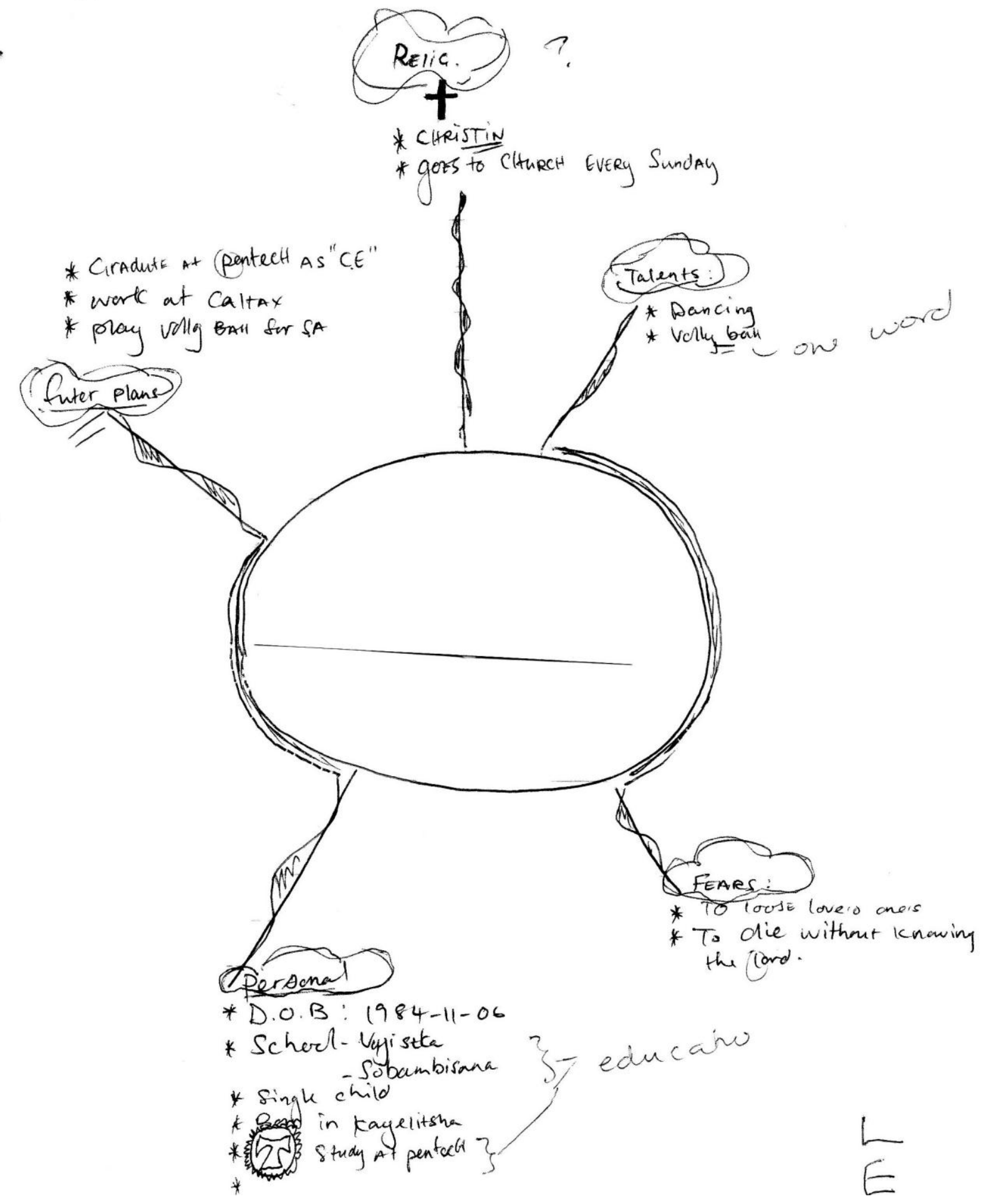

